\title{
Release Activity and Potential Ecological Risk Assessment of Heavy Metals in Coal Gangue of Hancheng, China
}

\author{
Li Wan-peng, Sun Ya-qiao, Yao Meng, Dou Lin \\ College of Environmental Science and Engineering, Chang'an University, Xi'an, Shanxi, China
}

\section{Email address:}

1284993588@qq.com (Li Wan-peng)

\section{To cite this article:}

Li Wan-peng, Sun Ya-qiao, Yao Meng, Dou Lin. Release Activity and Potential Ecological Risk Assessment of Heavy Metals in Coal Gangue of Hancheng, China. International Journal of Energy and Power Engineering. Vol. 4, No. 5, 2015, pp. 304-310. doi: 10.11648/j.ijepe.20150405.20

\begin{abstract}
Focused on release activity of different weather degree gangue of Han Cheng, evaluate heavy metals potential release risks by Hakanson instrument. The results showed that the content of heavy metals were more than their background in unweathered gangue. The Sang shuping gangue were $\mathrm{Cd}, \mathrm{Cr}$ and $\mathrm{As}$, so did $\mathrm{Cd}, \mathrm{Pb}, \mathrm{Cr}, \mathrm{Cu}, \mathrm{Ni}$ and $\mathrm{As}$ in $\mathrm{Xia}$ yukou. Residue fraction were the main fraction of heavy metals in gangue. The release potential and activity of heavy metals decreased with the weather degree increasing. The release activity of unweathered and weathered one year of Sang shuping gangue from high to low were $\mathrm{Cu}, \mathrm{Pb}, \mathrm{Ni}, \mathrm{Cd}, \mathrm{Cr}$, As and $\mathrm{Cd}, \mathrm{Pb}, \mathrm{Cu}, \mathrm{Ni}, \mathrm{Cr}$, As respectively. The release activity of unweathered and weathered one year of Xia yukou gangue from high to low were $\mathrm{Cu}, \mathrm{Ni}, \mathrm{Cr}, \mathrm{Pb}, \mathrm{Cd}$, As. The potential ecological risk of heavy metals were in slight degree, and the potential risk index of heavy metals decreased gradually with the increasing of weather degree. The potential risk index of heavy metals from high to low were $\mathrm{Cd}, \mathrm{Pb}, \mathrm{Cu}, \mathrm{Ni}, \mathrm{As}, \mathrm{Cr}$ and $\mathrm{Cd}, \mathrm{Cu}, \mathrm{Pb}, \mathrm{Ni}, \mathrm{Cr}$, As respectively.
\end{abstract}

Keywords: Coal Gangue, Heavy Metals, Release Activity, Potential Ecological Risk Assessment

\section{Introduction}

Coal gangue is a kind of solid waste generated in the washing and mining process [1-3]. At present coal gangue has been accumulated about five billion tons in China, at the same time it is increasing about 200 million tons year by year. Coal gangue is mainly used for power generation and manufacture of building materials in China [4]. A lot of open-air pile of coal gangue accumulatied, because of a low utilization rate about $30 \%$. Soil and water environment even human health nearby were effected by heavy metals pollution element, which release more in long-term weathered and eluviated [5-11]. The coal gangue which deposited in the open air produced a large number of poisonous gases such as $\mathrm{H} 2 \mathrm{~S}$, $\mathrm{SO} 2$, which harmed residents health and effected the growth of plants at Yangquan city, Shanxi Province [12]. The coal gangue which deposited outside for a long time resulted in plenty of salt to dissolve into water.And contaminated the groundwater at Yanzhou city, Shandong Province [13]. Finkelman pointed the release activity and toxicity of heavy metals have a lot of relations to its forms, which determing the ability of heavy metal elements release to the environment [14]. This article, which using Tessier five consecutive step extraction to confirm exchangeable form, carbonate bound, Fe-Mn oxides bound, organic bound and residual form heavy metal content and to research the release characteristic of different weathering degree of coal gangue and to evaluate the potential ecological risk.In order to provide a basis for the governance in mining pollution repairmen [15].

\section{Materials and Methods}

\subsection{Sampling Area Profile}



Fig. 1. The schematic of sampling district. 
Hancheng city is located in the guanzhong basin and northern shaanxi loess plateau transition zone, YiChuan close to the north, HeYang joint to the south, the Yellow River across to the east the and Huanglong to the west. Mining area is located in the northeast of weihe coal field, according to the geological structure divided it into two parts.North part including Sang shuping, Liao yuan and Xia yukou three coal fields, south part including Xiang shan coal field. These mining fields stack more than 500 thound tons coal gangue and affect the surrounding ecological environment.

\subsection{Experimental Method}

Respectively collect Xia yukou and Sang shuping two different weathering degree of coal gangue heap of eight samples on April 27, 28, 2011 and May 14, 15, 2014. In the process of sampling use GPS positioning and the stainless steel shovelling $1 \mathrm{~kg}$ coal gangue in plastic bags. We take the unweathered and different weathered degree coal gangue back to the laboratory.

Then we place the samples at dry air to speed up the natural weathering.After smashed by mortar we get the final samples which could through the 100 mesh nylon mesh.

Using Tessier five consecutive step extraction to analyse heavy metals of exchangeable form, carbonate bound, Fe-Mn oxides bound, organic bound and residual form in the coal gangue. We use Inductively Coupled Plasma Optical Emission Spectrometer (ICP-OES) to analyse the heavy metals.

In order to reduce the random error and improve data reliability and accuracy of samples, this study conducted parallel experiment to confirm experimental data reliability.

\section{Results}

\subsection{Heavy Metal Content in Gangue}

From table 1 we see that the $\mathrm{Cd}, \mathrm{Cr}$ and As contents in unweathered coal gangue of Sang shuping are much higher than China soil background value [16]. The times to the China soil background value are $31.75,1.65$ and 15.48 respectively. The $\mathrm{Cd}, \mathrm{Pb}, \mathrm{Cr}, \mathrm{Cu}, \mathrm{Ni}$ and As contents in unweathered coal gangue of Xia yukou are much higher than China soil background value.The times to the China soil background value are $568.75,39.2,2.83,1.26,1.76$ and 45.56 respectively. The heavy metal contents in Xia yukou mine are obviously higher than that of Sang shuping mine.

Dates from figure 2 show that the heavy metal contents of weathering one year time in Sang shuping dropped sharply. By the time of weathering two years it rised slightly. This phenomenon show that the release potential of heavy metals of weathering one year is maximum. Then the release potential of heavy metals decline with the increasing of the weathering degree. The heavy metals of weathering five years (such as $\mathrm{Pb}$, $\mathrm{Cu}, \mathrm{Ni}$ ) content are a little more than the unweathered samples. This is likely to be the earlier weathered samples releasing heavy metals into the atmosphere, where heavy metals particles sedimentating. Dates from figure 3 show that in addition to the $\mathrm{Cr}$ element the rest are obvious downward trend in this five years in Xia yukou mine gangue. Continuous weathering in coal gangue make the heavy metal contents in surrounding environment accumulate. Affecting the environmental quality and harming human health [17-18].

Table 1. Concentration of heavy metals in Gangue.

\begin{tabular}{|c|c|c|c|c|c|c|c|}
\hline & & Cd & $\mathbf{P b}$ & $\mathrm{Cr}$ & $\mathbf{C u}$ & $\mathrm{Ni}$ & As \\
\hline \multicolumn{2}{|c|}{$\begin{array}{l}\text { China soil } \\
\text { background values }\end{array}$} & 0.08 & 23.50 & 57.30 & 20.70 & 24.90 & 9.60 \\
\hline \multirow{4}{*}{$\begin{array}{l}\text { Sang } \\
\text { Shu } \\
\text { ping }\end{array}$} & unweathered & 2.54 & 19.26 & 94.77 & 13.70 & 9.29 & 148.59 \\
\hline & 1 year & 0.04 & 2.28 & 35.74 & 6.20 & 6.03 & 45.56 \\
\hline & 2 year & 1.80 & 16.40 & 78.64 & 9.06 & 8.62 & 128.07 \\
\hline & 5 year & 0.53 & 21.40 & 87.50 & 18.24 & 27.02 & 67.57 \\
\hline \multirow{4}{*}{$\begin{array}{l}\text { Xia } \\
\text { Yu } \\
\text { kou }\end{array}$} & unweathered & 45.50 & 921.13 & 162.38 & 26.13 & 43.75 & 437.38 \\
\hline & 1 year & 6.88 & 217.25 & 176.88 & 21.13 & 43.73 & 398.75 \\
\hline & 2 year & 19.63 & 276.13 & 170.88 & 23.63 & 41.63 & 442.13 \\
\hline & 5 year & 3.79 & 64.17 & 163.66 & 16.41 & 22.44 & 244.85 \\
\hline
\end{tabular}

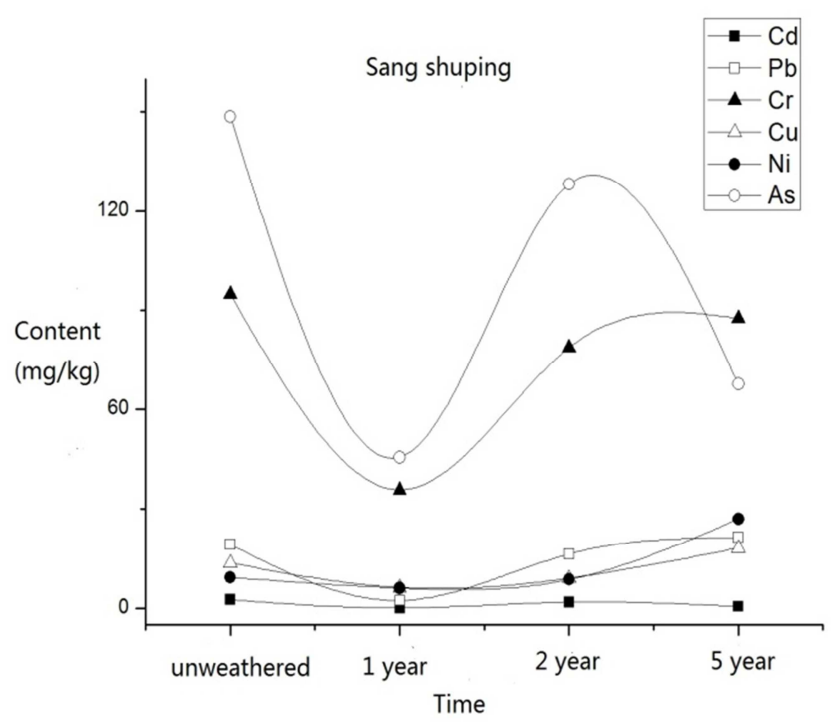

Fig. 2. Concentration of heavy metals in Gangue along with the weathering time variation of Sang shuping.

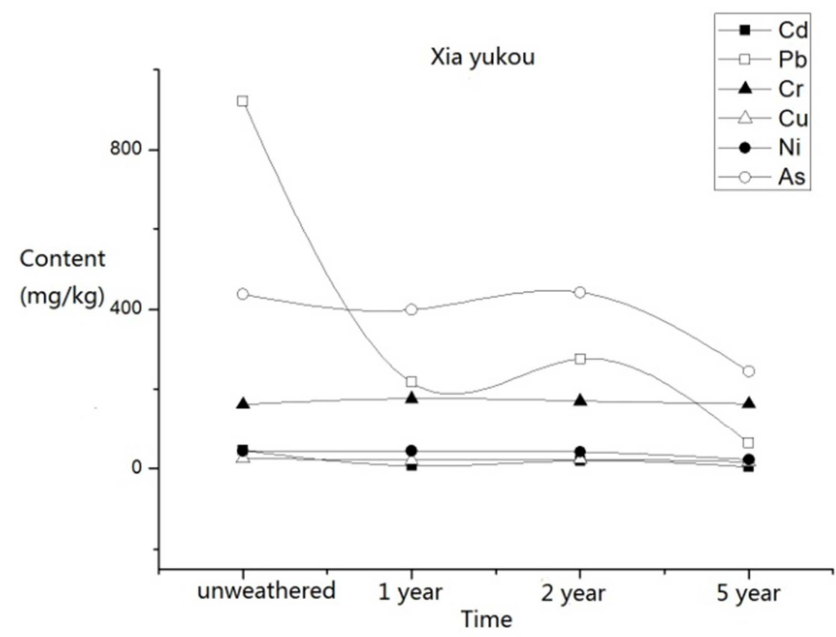

Fig. 3. Concentration of heavy metals in Gangue along with the weathering time variation of Xia yukou. 
The release potential of heavy metals are the highest in the first year of Sang shuping and Xia yukou.Then the release potential decreases gradually with the increasing of weathering degree. The heavy metal contents of Xia yukou are much higer than the Sang shuping, whch have a obviously release like $\mathrm{Pb}$ and As during five years weathering.

\subsection{Gangue Geochemical Forms of Heavy Metals}

From table 2 we see that the mine heavy metal form is residual. $\mathrm{Cd}, \mathrm{Cr}, \mathrm{Ni}, \mathrm{As}$ contents pass more than $90 \%$ and $\mathrm{Pb}$, $\mathrm{Cu}$ also pass more than $85 \%$ in unweathered Sang shuping gangue. In weathering one year gangue, only $\mathrm{Cr}$ and $\mathrm{As}$ contents pass $90 \%$. $\mathrm{Cd}$ and $\mathrm{Pb}$ are main in Fe-Mn oxides bound (44.12\% and $42.05 \%)$. Cd in exchangeable form is $29.41 \%, \mathrm{~Pb}$ in organic bound is $23.30 \%, \mathrm{Cd}$ in residual form is zero. Weathering two years and five years gangue are main in residual form. Only the exchangeable form of $\mathrm{Cu}$ are more than $10 \%(18.20 \%, 10.55 \%$ respectively). In weathering five years gangue, only $\mathrm{Pb}$ carbonate bound is more than $10 \%$ $(11.67 \%)$. The other heavy metals in first four forms do not exceed $10 \%$. Except the residue form the rest four forms of heavy metals all have biological effectiveness. This article analyzes the heavy metal release of the first four forms: exchangeable form, carbonate bound, Fe-Mn oxides bound and organic bound [19]. The heavy metals realse activity of unweathered and weathering two years from high to low are $\mathrm{Cd}, \mathrm{Pb}, \mathrm{Ni}, \mathrm{Cd}, \mathrm{Cr}$ and As. The weathering one year are $\mathrm{Cd}, \mathrm{Cu}$, $\mathrm{Ni}, \mathrm{Cr}$ and $\mathrm{As}$. The weathering five years are $\mathrm{Pb}, \mathrm{Cu}, \mathrm{Cd}, \mathrm{Ni}$, $\mathrm{Cr}$ and As.

Table 2. The percentage of various fraction of heavy metals in coal gangue of Sang shuping.

\begin{tabular}{|c|c|c|c|c|c|c|c|}
\hline Time & Form & Cd & $\mathbf{P b}$ & $\mathrm{Cr}$ & $\mathrm{Cu}$ & $\mathbf{N i}$ & As \\
\hline \multirow{5}{*}{ unweathered } & exchangeable & 0.34 & 0.14 & 0.01 & 0.01 & 0.83 & 0.06 \\
\hline & carbonate & 0.15 & 2.42 & 0.03 & 1.24 & 0.98 & 0.00 \\
\hline & Fe-Mn & 0.69 & 3.30 & 0.10 & 0.04 & 1.39 & 0.00 \\
\hline & organic & 0.25 & 5.86 & 0.15 & 12.93 & 5.33 & 0.00 \\
\hline & residual & 98.57 & 88.28 & 99.71 & 85.78 & 91.47 & 99.94 \\
\hline \multirow{5}{*}{1 year } & exchangeable & 29.41 & 2.14 & 0.02 & 0.14 & 2.40 & 0.13 \\
\hline & carbonate & 8.82 & 10.58 & 0.06 & 4.05 & 4.66 & 0.00 \\
\hline & Fe-Mn & 44.12 & 42.05 & 0.12 & 1.09 & 9.64 & 0.00 \\
\hline & organic & 17.65 & 23.30 & 0.48 & 18.12 & 4.54 & 0.00 \\
\hline & residual & 0.00 & 21.93 & 99.32 & 76.60 & 78.76 & 99.87 \\
\hline \multirow{5}{*}{2 year } & exchangeable & 0.56 & 0.30 & 0.01 & 0.15 & 0.55 & 0.06 \\
\hline & carbonate & 0.69 & 4.21 & 0.07 & 6.91 & 3.19 & 0.00 \\
\hline & $\mathrm{Fe}-\mathrm{Mn}$ & 1.11 & 6.62 & 0.15 & 0.22 & 3.64 & 0.00 \\
\hline & organic & 0.35 & 3.48 & 0.26 & 18.20 & 2.75 & 0.00 \\
\hline & residual & 97.29 & 85.39 & 99.51 & 74.52 & 89.87 & 99.94 \\
\hline \multirow{5}{*}{5 year } & exchangeable & 2.52 & 0.06 & 0.01 & 0.04 & 0.14 & 0.10 \\
\hline & carbonate & 2.06 & 11.67 & 0.06 & 7.09 & 1.81 & 0.00 \\
\hline & $\mathrm{Fe}-\mathrm{Mn}$ & 2.52 & 6.62 & 0.21 & 0.46 & 2.47 & 0.00 \\
\hline & organic & 1.15 & 3.11 & 0.21 & 10.55 & 1.72 & 0.00 \\
\hline & residual & 91.75 & 78.54 & 99.51 & 81.86 & 93.86 & 99.90 \\
\hline
\end{tabular}

From table 3 we see that the mine heavy metal form is residual form. $\mathrm{Cr}, \mathrm{Pb}, \mathrm{Cd}$, As contents pass more than $90 \%$ in $\mathrm{Xia}$ yukou unweathered gangue. $\mathrm{Cu}$ is main in organic bound (76.97\%) and carbonate bound is $12.92 \%$ however the residual form is only $4.31 \%$. Ni is main in residual form $(76.57 \%)$ and organic bound is $11.86 \%$, the rest three forms are no more then $10 \%$. The residual form are all more than $80 \%$ except $\mathrm{Cu}$, which is main in organic bound (74.2\%). Carbonate bound and Fe-Mn oxides bound are more than $10 \%$ in weathering one year. Except $\mathrm{Cu}$ and $\mathrm{Ni}$ the rest heavy metals in residual form are more than $90 \%$. $\mathrm{Cu}$ is still main in organic bound $(71.23 \%)$ and the residual form is $(12.39 \%)$. $\mathrm{Ni}$ is main in residual form $(77.98 \%)$ and the Fe-Mn oxides bound is $12.32 \%$ in weathering two years. The heavy metals in gangue of Xia yukou are over $90 \%$ in residual form. The release activity of heavy metals in unweathered, weathering one year and two years from hiagh to low are $\mathrm{Cu}, \mathrm{Ni}, \mathrm{Cr}, \mathrm{Pb}, \mathrm{Cd}$ and $\mathrm{As}$. The weathering five years are $\mathrm{Cu}, \mathrm{Ni}, \mathrm{Cd}, \mathrm{Pb}, \mathrm{Cr}$ and $\mathrm{As}$.

Table 3. The percentage of various fraction of heavy metals in coal gangue of Xia yukou.

\begin{tabular}{|c|c|c|c|c|c|c|c|}
\hline Time & Form & Cd & $\mathbf{P b}$ & $\mathrm{Cr}$ & $\mathrm{Cu}$ & $\mathbf{N i}$ & As \\
\hline \multirow{5}{*}{ unweathered } & exchangeable & 0.03 & 0.00 & 0.02 & 0.80 & 0.07 & 0.00 \\
\hline & carbonate & 0.01 & 0.46 & 0.12 & 12.92 & 3.43 & 0.00 \\
\hline & Fe-Mn & 0.08 & 0.88 & 3.18 & 5.00 & 8.07 & 0.00 \\
\hline & organic & 0.20 & 0.93 & 2.31 & 76.97 & 11.86 & 0.00 \\
\hline & residual & 99.68 & 97.73 & 94.37 & 4.31 & 76.57 & 100 \\
\hline \multirow{5}{*}{1 year } & exchangeable & 0.51 & 0.00 & 0.01 & 1.63 & 0.00 & 0.00 \\
\hline & carbonate & 0.51 & 1.08 & 0.10 & 11.02 & 2.73 & 0.00 \\
\hline & $\mathrm{Fe}-\mathrm{Mn}$ & 2.69 & 5.83 & 5.38 & 13.15 & 12.11 & 0.00 \\
\hline & organic & 1.02 & 0.91 & 2.40 & 74.20 & 4.33 & 0.00 \\
\hline & residual & 95.27 & 92.18 & 92.11 & 0 & 80.83 & 100 \\
\hline \multirow{5}{*}{2 year } & exchangeable & 0.32 & 0.00 & 0.01 & 1.26 & 0.00 & 0.00 \\
\hline & carbonate & 0.27 & 0.85 & 0.17 & 6.07 & 2.86 & 0.00 \\
\hline & $\mathrm{Fe}-\mathrm{Mn}$ & 0.57 & 2.76 & 3.60 & 9.05 & 12.32 & 0.00 \\
\hline & organic & 0.69 & 1.19 & 4.40 & 71.23 & 6.84 & 0.00 \\
\hline & residual & 98.15 & 95.20 & 91.82 & 12.39 & 77.98 & 100 \\
\hline \multirow{5}{*}{5 year } & exchangeable & 0.40 & 0.37 & 0.01 & 3.33 & 3.97 & 0.04 \\
\hline & carbonate & 0.30 & 0.06 & 0.03 & 1.75 & 1.25 & 0.00 \\
\hline & $\mathrm{Fe}-\mathrm{Mn}$ & 0.30 & 0.13 & 0.08 & 1.57 & 1.24 & 0.00 \\
\hline & organic & 0.13 & 0.08 & 0.13 & 1.96 & 1.06 & 0.00 \\
\hline & residual & 98.87 & 99.36 & 99.75 & 91.39 & 92.48 & 99.96 \\
\hline
\end{tabular}

The release activity of Sang shuping and Xia yukou gangue are decreased with the increasing of the weathering degree. Both heavy metals release activity of two mines are very high during the first two years weathering.In the first year weathering, $\mathrm{Cd}$ and $\mathrm{Pb}$ are mine in Fe-Mn oxides bound, in which the oxidation stability condition is poor.As time goes on the potential of polluting to environment is increasing.Cd is main in exchangeable form, in which the heavy metal is extremely sensitive to environmental change.In the first two years weathering of $\mathrm{Xia}$ yukou, $\mathrm{Cu}$ is main in organic 
bound.In the condition of oxidation, this form can change into $\mathrm{Fe}-\mathrm{Mn}$ oxides bound or carbonate bound, which can increase the release activity of heavy metals. $\mathrm{Cu}$ is more than $10 \%$ in carbonate bound, in which form the heavy metals particularly sensitive to $\mathrm{pH}$ change and easily to release under acidic water leaching.With the weathering degree increasing, heavy metals are main in residual form.In this form the gangue is stable.But with the weathering time increasing, the coal gangue lattice, which can result in the decrease of coal gangue residue form stability is easy broken.

\subsection{The Potential Ecological Risk Assessment of Heavy Metals}

This article uses Hakanson potential ecological harm index method to evaluate the potential risk of heavy metals in coal gangue. This method is widely used in the analysis of quantitative, types, levels of toxicity and risk assessment of heavy metal content [20-22]. According to the first four forms' dates, we evaluate the potential ecological risk assessment. The calculating formula is $R I=\sum_{i=1}^{n} E_{r}^{i}=\sum_{i=1}^{n} T_{r}^{i} C_{r}^{i}=\sum_{i=1}^{n} T_{r}^{i} C_{a}^{i} / C_{n}^{i}$

$C_{a}^{i}$ means the actual measurment of heavy metal element content. $C_{n}^{i}$ means the soil element background values(table 1). $C_{r}^{i}$ means the single pollution index of heavy metal element. $T_{r}^{i}$ means heavy metal toxicity response coefficient, which reflects the strength of toxicity and the sensitivity of heavy metal in water $(\mathrm{Cd}, \mathrm{Pb}, \mathrm{Cr}, \mathrm{Cu}, \mathrm{Ni}, \mathrm{As}$, respectively are $30,5,2,5,5,10)$ [23]. $E_{r}^{i}$ means the potential ecological harm coefficient of heavy metal. RI means the comprehensive index of potential ecological harm of heavy metal. (table 4)

Table 4. The classification standard of potential ecological risk assessment.

\begin{tabular}{llllll}
\hline$C_{r}^{i}$ & $\begin{array}{l}\text { single element } \\
\text { pollution level }\end{array}$ & $E_{r}^{i}$ & potential ecological level & $R I$ & $\begin{array}{l}\text { Comprehensive potential } \\
\text { ecological risk degree }\end{array}$ \\
\hline$<1$ & slight & $<40$ & slight & $<150$ & slight \\
{$[1,3)$} & medium & {$[40,80)$} & medium & {$[150,300)$} & medium \\
{$[3,6)$} & strong & {$[80,160)$} & strong & {$[300,600)$} & strong \\
$>6$ & Very strong & {$[160,320)$} & Very strong & {$[600,1200)$} & Very strong \\
& & $>320$ & fortissimo & $>1200$ & fortissimo \\
\hline
\end{tabular}

From table 5 we can see that the comprehensive potential risk index of heavy metals in Sang shuping and Xia yukou gangue are in slight degree.Figure 4 and figure 6 show that the potential ecological risk of heavy metals in Sang shuping are in slight degree. With the increasing of weathering degree, the potential ecological risk change is gradual small.The potential risk of $\mathrm{Cd}$ is the highest. Figure 5 and figure 7 show that in addition to $\mathrm{Cd}$ the other heavy metal elements potential risk index in Xia yukou gangue are in slight degree. With the weathering degree increasing, the degree of risk shows a downward trend. The potential risk of $\mathrm{Cd}$ is the highest, which has a strong dangerous degree of weathering in first two years. With the weathering degree increasing, the risk reduces to slight degree. The coefficient of potential ecological risk and the comprehensive potential ecological index of heavy metals in Xia yukou gangue are higher than that in Sang shuping gangue, which has a higher potential release risk of heavy metals.

The comprehensive potential ecological risk of heavy metals in Xia yukou gangue is in slight degree. With the weathering degree increasing, the potential ecological risk reduce to a slight degree, which still has a high potential release of heavy metals. The gangue which pile up long time can pollute the environment.So in the process of comprehensive utilization we need to pay attention to environmental protection.

Table 5. The results of potential ecological risk assessment.

\begin{tabular}{|c|c|c|c|c|c|c|c|c|}
\hline \multirow{2}{*}{ time } & \multicolumn{6}{|l|}{$E_{r}^{i}$} & \multirow{2}{*}{$R I$} & \multirow{2}{*}{ Risk level } \\
\hline & Cd & $\mathbf{P b}$ & $\mathrm{Cr}$ & $\mathbf{C u}$ & $\mathbf{N i}$ & As & & \\
\hline Unweathered of Sang shuping & 13.95 & 0.48 & 0.01 & 0.47 & 0.16 & 0.09 & 14.80 & slight \\
\hline 1 year & 15.94 & 0.38 & 0.01 & 0.35 & 0.26 & 0.06 & 17.00 & slight \\
\hline 2 year & 18.28 & 0.51 & 0.01 & 0.56 & 0.18 & 0.08 & 19.61 & slight \\
\hline 5 year & 16.88 & 1.05 & 0.01 & 0.80 & 0.34 & 0.07 & 19.15 & slight \\
\hline Unweathered of Xia yukou & 54.38 & 4.44 & 0.01 & 6.04 & 2.06 & 0.00 & 66.92 & slight \\
\hline 1 year & 121.88 & 3.62 & 0.01 & 5.26 & 1.68 & 0.00 & 132.44 & slight \\
\hline 2 year & 135.94 & 2.82 & 0.01 & 5.00 & 1.84 & 0.00 & 145.61 & slight \\
\hline 5 year & 15.94 & 0.09 & 0.01 & 0.34 & 0.34 & 0.10 & 16.82 & slight \\
\hline
\end{tabular}



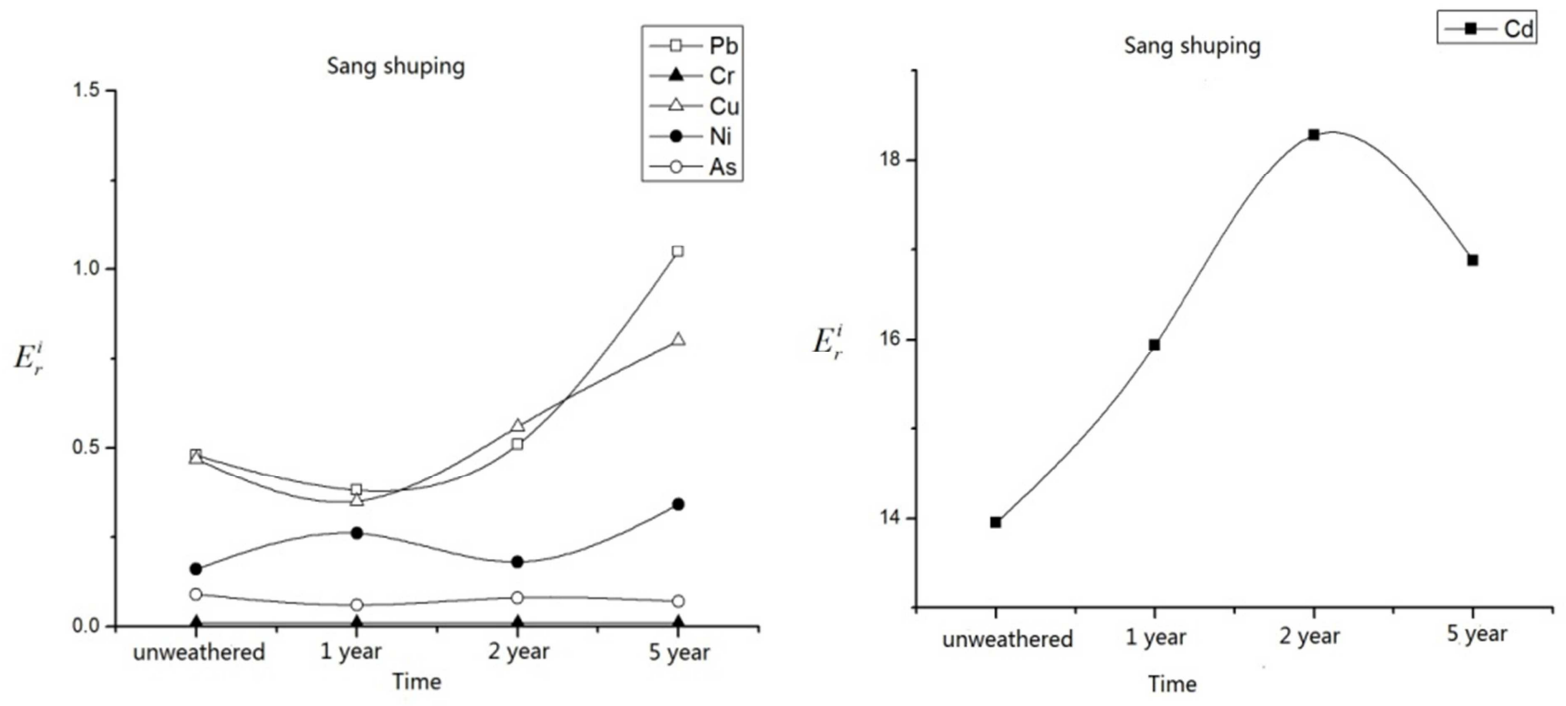

Fig. 4. The potential ecological risk of heavy metals of Sang shuping coal gangue.
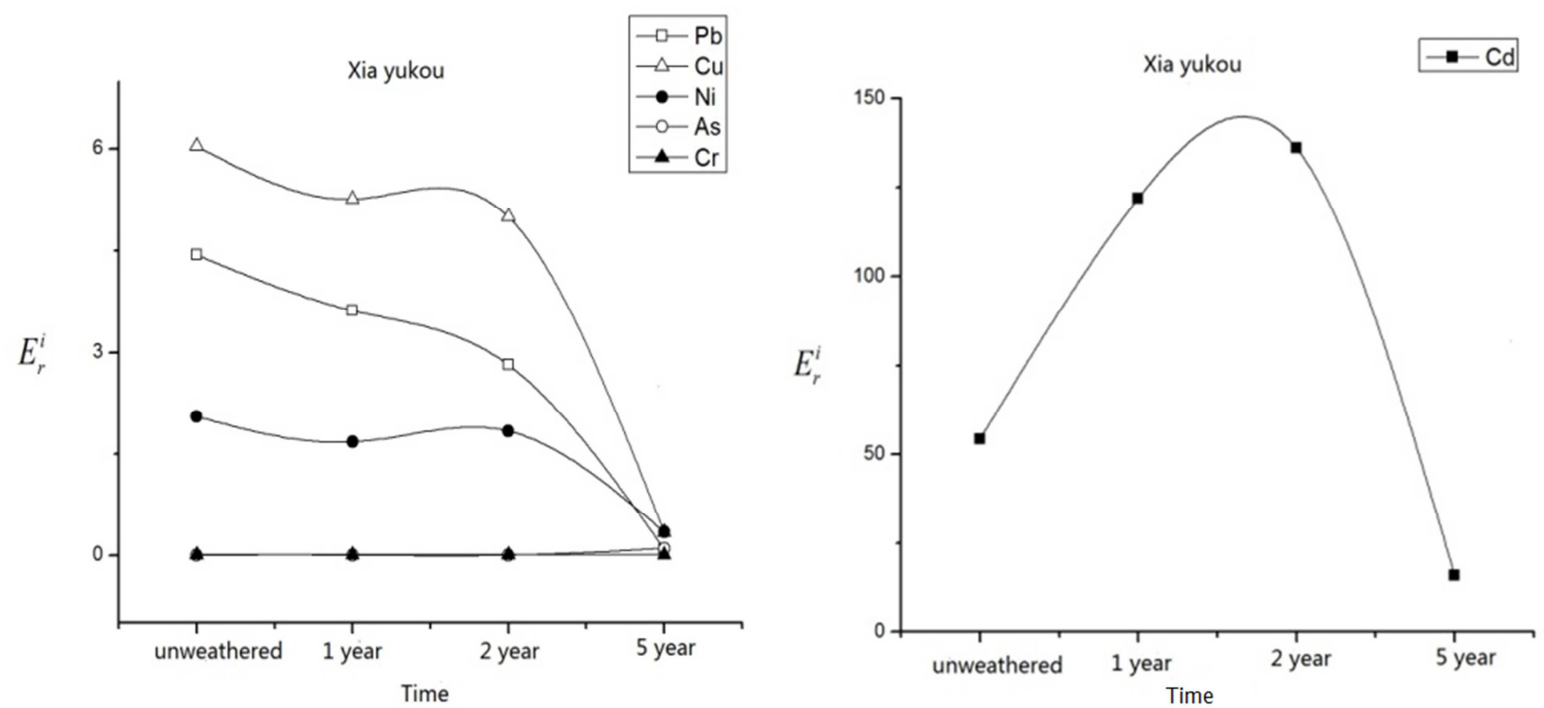

Fig. 5. The potential ecological risk of heavy metals of Xia yukou coal gangue.


Fig. 6. The synthetic potential risk index of Xia yukou coal gangue. 


\section{Conclusion}

(1) In Sang shuping and Xia yukou unweathered gangue, the heavy metals $\mathrm{Cd}, \mathrm{Cr}$, As and $\mathrm{Cd}, \mathrm{Pb}, \mathrm{Cr}, \mathrm{Cu}, \mathrm{Ni}$, As are more than China soil background value respctively. The heavy metal release potential of Xia yukou mine is obviously higher than that of Sang shuping. In the first weathering year, the heavy metals have the biggest release potential. Then the content decrease with weathering degree increasing.

(2) With the weathering degreee increasing, the release activity of two mine gangue decrease.In first two years weathering, the release activity of heavy metals are high. In the first year weathering, $\mathrm{Cd}$ and $\mathrm{Pb}$ are mine in Fe-Mn oxides bound, in which the oxidation stability condition is poor. In the first two years weathering of Xia yukou, $\mathrm{Cu}$ is main in organic bound.In the condition of oxidation, this form can change into $\mathrm{Fe}-\mathrm{Mn}$ oxides bound or carbonate bound, which can increase the release activity of heavy metals. $\mathrm{Cu}$ is more than $10 \%$ in carbonate bound, in which form the heavy metals particularly sensitive to $\mathrm{pH}$ change and easily to release under acidic water leaching. With the increasing of weathering degree, heavy metals are main in residual form, which is stable can not be easily replaced by the silicate mineral. But with the weathering time increasing, the coal gangue lattice, which can result in the decrease of coal gangue residue form stability is easy broken.

(3) The heavy metals potential ecological risk in Sang shuiping from high to low is $\mathrm{Cd}, \mathrm{Pb}, \mathrm{Cu}, \mathrm{Ni}, \mathrm{As}, \mathrm{Cr}$.The heavy metals potential ecological risk in Xia yukou from high to low is $\mathrm{Cd}, \mathrm{Cu}, \mathrm{Pb}, \mathrm{Ni}, \mathrm{Cr}$, As. The coefficient of potential ecological risk and the comprehensive potential ecological index of heavy metals in Xia yukou gangue are higher than that in Sang shuping gangue, which has a higher potential release risk of heavy metals. The potential ecological risk of heavy metals in two mine gangue are in slight degree. With the increasing of the weathering degree the potential ecological risk gradually reduce.

\section{Acknowledgements}

Fund program Natural Science Foundation of China (41002086, 41372258), Shaanxi Provincial Natural Science Foundation (2013JM5003), The central college scientific research fund (2013G1291065, 2013G1291067, 2013G1502036), The key laboratory of mine comprehensive utilization and resources exploration in shaanxi province, China sustenation funds (2014HB006).

\section{References}

[1] Zhou Chuang, Dan song. The dangers of coal gangue and resource utilization technology research [J]. Inner Mongolia Environmental Science, 2008, 20(4): 32-35.

[2] Liu di. The environmental hazards of coal gangue and comprehensive utilization research [J]. Journal of Meteorology and Environment, 2006, 22(3): 60-62.
[3] Zhang jianqiang. The environmental impact of coal gangue mountain and governance $[\mathrm{J}]$. The Coke Coal Science and Technology of Shanxi, 2009(2): 44-46.

[4] Wang xinfeng, Gao mingzhong, Fang xiaomin. The new exploration of mining area comprehensive utilization of coal gangue [J]. Coal Technology, 2012(4): 50-53.

[5] Cui Longpeng, Bai Jianfeng, Shi Yonghong, etal. Study on soil heavy metals pollution from mining acitivity $[\mathrm{J}]$. Acta Pedologica Sinica, 2004, 41(6): 898-904.

[6] Li Xuhua, Wang Xinyi, Yang Jian, etal. Review on heavy metal pollution to soil and corn near coal waste rock dump in Jiaozuo diggings [J]. Environmental Protection Science, 2009, 35(2): $66-69$.

[7] Cai Feng, Liu Zegong, Lin Baiquan, et al. Study on trace elements in gangue in Huainan mining area [J]. Journal of China Coal Society, 2008, 33(8): 892-897.

[8] Wang Xinyi, Yang Jian, Guo Huixia. Study on heavy metals in soil contaminated by coal waste rock pile [J]. Journal of China Coal Society, 2006, 31(6): 808-812.

[9] Zhang Li, Han Guocai, Chen Hui, et al. Study on heavy metal contaminants in soil from coal mining spoil in the Loess plateau[J]. Journal of China Coal Society, 2008, 33(10): 1141-1146.

[10] Chai shiwei, Wen suomao, Wei xiange. The characteristics of heavy metal content in agricultural soil of suburbs and major cities in the pearl river delta [J]. Journal of China Coal Society, 2000, 17(2): 42-44.

[11] Hanson M L, Solomon K R. New technique for estimating thresholds of toxicity in ecological risk assessment [J]. Environmental Science Technology, 2002, 36: 3257-3764.

[12] Zheng guoqiang, Zhang chengliang, Zhang hongjiang, etal. Effect of temperature on water content of coal gangue and plant growth [J]. Chinese Journal of Soil Science, 2008, 6(3): $107-111$.

[13] Wu xiaohua, Ye jin xia, Xia chunying, etal. Yanzhou coal mine geological environment field Situation and Countermeasures [J]. Coal Geology \& Exploration, 2008, 36(1): 53-57.

[14] Liu guijian, Yang ping, Peng zicheng. Potentially harmful trace elements in coal gangue leaching precipitation research $[\mathrm{J}]$. Geological Journal of China Universities, 2001.

[15] Tessier A, Campbell P G C, Bisson M. Sequen2 tail extraction procedure for the speciation of particulate trace metals. Anal. Chem, 1976(51): 844 850.

[16] Wei fusheng, Yang guozhi. The element background values basic statistics and characteristics of China soil [J]. Environmental Monitoring in China, 1991. 7(1)21-26.

[17] $\mathrm{Wu}$ daishe, Zheng baoshan, Kang wangdong. The leaching behavior and environmental influence research of coal gangue - use huainan pan xie mining area as an example [J]. Earth and Environment, 2004, 32(1): 55-59.

[18] Wei zhongyi, Lu liang, Wang qiubing. Research of open-pit mine and its surrounding soil heavy metal pollution of large coal gangue mountain in west Fushun [J]. Chinese Journal of Soil Science, 2008, 39(4)946-949. 
[19] Xing ning, Wu pingxiao, Li yuanyuan etal. Dabaoshan tailings heavy metals speciation and potential migration of analysis [J]. Journal of Environmental Engineering, 2011, 5(6): 1370-1374

[20] Zhang mingliang, Yue xingling, Yang shuying. Release activity of heavy metals in coal gangue and potential ecological risk assessment of contaminated soil [J]. Journal of soil and water conservation, 2011, 25(4): 249-252.

[21] Chen jinghui, Lu xinwei, Zhai meng. The sources of soil heavy metal and potential risks in $\mathrm{Xi}$ 'an city roadside $[\mathrm{J}]$. Chinese Journal of Applied Ecology, 2011, 7(22): 1810-1816.

[22] Ma xiaofeng. The soil heavy metal pollution and ecological risk assessment of Harbin city [D]. Harbin: Northeast Forestry University Harbin, 2009: 1-50.

[23] Lars Hakanson. An ecological risk index for aquatic pollution control. A sedimentological approach [J]. Water Research, 1980, 14(8): 975-1001. 